Orbis Tertius, vol. XXIV, $\mathrm{n}^{\circ}$ 29, e118, mayo-octubre 2019. ISSN 1851-7811

Universidad Nacional de La Plata

Facultad de Humanidades y Ciencias de la Educación

Centro de Estudios de Teoría y Crítica Literaria

\title{
Guillermo Korn y Matías Farías, Desierto y nación II: Estados. Ciudad Autónoma de Buenos Aires, Caterva, 2018, Desierto y nación, 160 páginas
}

Poniendo como eje de reflexión el concepto de "estados", este segundo volumen de la colección Desierto y nación - título con resonancias al clásico de Halperin Donghi, Una Nación para el Desierto Argentinoreúne entre sus páginas una serie de ensayos sobre Lucio V. Mansilla y José Martí, dos personajes clave del último tercio del siglo XIX, que si bien nunca se conocieron, ni se mencionaron mutuamente en sus escritos, tienen zonas de contacto, temas en común en su pensamiento y obra, prácticamente indistinguibles el uno de la otra.

Los hechos biográficos los colocan en roles protagónicos - bien diferentes entre sí- en ciertas fechas concretas. Para 1870, mientras Lucio V. Mansilla se internaba en las tolderías ranquelinas, un joven José Martí había sido tomado prisionero y condenado a trabajos forzados por la represión española que daría inicio a la "Guerra de los diez años". Hacia fines de la década de 1880, mientras Mansilla publicaba sus célebres Causeries en el diario oficialista Sud-América, Martí enviaba como corresponsal algunos de sus textos más representativos al periódico opositor La Nación. Como dato anecdótico, los nombres de Mansilla y Martí conviven en la misma página del ejemplar del 19 de junio de 1890 del periódico Sud-América, cuando el diario reproduce el texto La Argentina en Norte-América del escritor cubano y se publica en el espacio del folletín la causerie "Alucinación”.

Pero lo más importante es que entre ambos autores existen puntos de contacto con respecto a los modos de concebir los proyectos de nación, las conformaciones de los estados nacionales y las caracterizaciones de las alteridades, a la vez que cuestionan las ideas de uno de los intelectuales con mayor gravitación del siglo XIX: Sarmiento. Así, en su obra Una excursión a los indios ranqueles Mansilla brinda un imagen de los nativos que retuerce e incluso invierte ciertos lugares comunes sobre la otredad - construidos principalmente a partir de la dicotomía sarmientina "civilización y barbarie" - y que difieren radicalmente de las construcciones pergeñadas casi una década después, sobre todo por Estanislao Zeballos, como fondo ideológico para justificar la infame "Conquista del desierto" llevada a cabo por Roca, definitoria en la construcción del Estado nacional. Por su parte, Martí produce un cuerpo de pensamiento sobre la constitución de una "modernidad alternativa” a aquella que comienza a expandirse por el continente en base al modelo liberal estadounidense, y para ello construye una identidad alterna, de fuerte arraigo en la unidad latinoamericana, que bautiza con el nombre de "Nuestra América". En torno a estas y otras reflexiones se organizan los ensayos Mansillescas de Guillermo Korn y Nuestra América: una modernidad alternativa. Poesía y revolución en Martí de Matías Farías, dialogando críticamente sobre las concepciones del estado argentino y latinoamericano.

La serie de textos ensayísticos escritos por Korn y englobados bajo el título Mansillescas recorren prácticamente toda la obra de Lucio V. Mansilla, desde sus reconocidas Una excursión a los indios ranqueles y Causeries, pasando por títulos menos estudiados como su Rozas. Ensayo histórico-psicológico o sus tempranas obras de teatro, hasta textos dispersos en la prensa periódica como Cartas de Amambay o Diario de un expatriado - reunidos en libro gracias al trabajo de Sandra Contreras. En estos "fotogramas de una cinta 
incompleta" - así describe Korn a sus ensayos-, el autor se propone abordar la obra de Mansilla con la intención de encontrar y sacar a relucir - pensemos en el poncho ranquelino por cuyos agujeros penetra la luz, imagen con la que se cierran los ensayos - esos rincones olvidados, esos momentos inéditos, esas conexiones aun no trazadas, que echan luz sobre la misma obra, sobre la historia, y tienden — "como puente" - enlaces hacia nuevas reflexiones sobre la actualidad.

Sin embargo, la labor del ensayista no resulta sencilla, pues en consonancia con la pregunta que abre el lúcido prólogo de Verónica S. Luna — “CCuánto más se puede decir sobre José Martí y Lucio V. Mansilla?”-, el propio autor reconoce el peso de otras lecturas fuertes de la obra de Mansilla, especialmente la de David Viñas, a la que podríamos sumar las de Julio Caillet-Bois, Silvia Molloy, Cristina Iglesia y Sandra Contreras. Para conseguir decir algo nuevo, Korn realiza un exorbitante trabajo de investigación y documentación, excavando entre archivos y periódicos —en la búsqueda de piezas de oro, como en la empresa minera de Mansilla, solo que con resultados afortunados en el caso de Korn-, en un gesto - que podríamos caracterizar como antieconómico y, por consiguiente, anticapitalista - de producir estos breves ensayos condensados a partir del relevamiento y estudio de una vastísima cantidad de documentación: artículos de una variedad de periódicos finiseculares, tales como El Nacional, el Correo del Domingo, La Tribuna, El Río de la Plata, El Chaco, El Diario, El Centinela, La Vanguardia, entre otros; el epistolario de varios personajes de la época, como Eduardo Wilde, J. A. Gelly y Obes o el propio Mansilla; estadísticas sobre un episodio de fiebre amarilla o apuntes a la Cámara de Senadores; textos de autores tan variados como Eduardo Schiaffino, Ernesto Quesada, Estanislao Zeballos, Santiago Arcos, José María Paz, Rivera Indarte, Juan Bialet Massé y otros; todo este material documental se entrecruza con la obra de Mansilla en los ensayos de Korn.

Teniendo siempre al excursionista como núcleo gravitacional de los textos, aparecen cruces e interrelaciones con otros personajes centrales del siglo XIX: en las mansillescas Don Juan Manuel y Músicos, bufones y filósofos se describe la relación con Juan Manuel de Rosas - y se sugieren paralelos entre este y Perón -; en De fiebres, religiones y olvidos aparece como figura central Eduardo Wilde y, de forma lateral, Julio A. Roca; todo el ensayo La pluma, la espada y la palabra trata sobre la conflictiva relación con Sarmiento y, en Un ilustrao bárbaro se trazan vínculos entre Mansilla y José Hernández. Pero las "mansillescas" no sólo abordan temáticas propias del siglo XIX, sino que además permiten extender las reflexiones hacia un pasado más cercano e incluso la actualidad: la mirada sobre la otredad en los viajes de Mansilla por Oriente, las ideas en torno al esclavo sometido y al buen salvaje, las estrategias pacíficas de defensa contra el indio -opuestas a la masacre y el exterminio que se concretaron en la realidad-, las alianzas políticas y sus consecuencias, los negociados y oportunismos políticos durante la guerra, la ambición de hacerse rico a través de empresas arriesgadas, la represión estatal a las luchas de los obreros a principios del siglo XX, los contrastes entre una ciudad rica y una mayoría de pobres que se alimentan de sobras; estos y otros tópicos que motivan una reflexión sobre el presente surgen de los pliegues de la obra de Mansilla cuando es escudriñada por la mirada atenta de Korn.

Si en las Mansillescas aparece la búsqueda minuciosa del erudito que recorre toda una obra tratando de poner en primer plano una serie de zonas y conexiones inéditas, en el ensayo Nuestra América... de Matías Farías el procedimiento parece ser el de remarcar, poner en relieve, las ideas y los conceptos fundamentales de los textos más importantes de la obra martiana, y unirlos en una serie consecutiva y coherente que permita hilvanar los caminos recorridos por José Martí en su tarea de pensar formas alternativas de la modernidad en Latinoamérica.

Para la construcción de sus ensayos Farías recorre toda la obra de Martí —emplea la edición crítica de las Obras Completas realizada por el Centro de Estudios Martianos, publicada de forma digital, con acceso abierto en línea, por CLACSO_, centrándose en los textos más reconocidos y estudiando las ideas fundamentales, para entrelazarlas en la construcción de una narrativa que nos permita seguir de cerca el recorrido de todo el pensamiento martiano. El eje está colocado en textos como el prólogo a El poema del Niágara, en las principales Escenas norteamericanas y en hitos de su pensamiento "nuestro americano", como 
los discursos Madre América y el célebre Nuestra América. Pero además, orbitan en torno a estos toda una serie de textos menos conocidos que pueden conectarse con aquellos para arrojar luz sobre la obra martiana: manifiestos, folletos, parte del epistolario, publicaciones de diversa índole en la prensa periódica, entre otros.

Los ensayos de Farías se proponen un estudio crítico y riguroso de todo este cuerpo de textos, con la intención de explicar una serie de tensiones que se presentan en el pensamiento y la obra martiana: la conflictiva intersección entre una "lírica esteticista" y una "épica revolucionaria" - cruce que funciona como definición del sujeto "nuestroamericano"-; la inicial fascinación por la modernidad en los Estados Unidos, que luego se convertirá en rechazo a favor de una forma alternativa de modernidad a construir en la unidad de América Latina - Nuestra América - y, el pasaje de la interioridad del yo lírico - “Soy el verso", escribía Martí en el poema XVII de Versos sencillos - al sujeto colectivo politizado que constituirá con su famoso sintagma "Nuestra América". De todo esto surge el trayecto de pensamiento de José Martí: una primera etapa juvenil revolucionaria — sellada por el encarcelamiento y el trabajo forzado-, un poeta lírico marcado por el exilio que se repliega hacia la interioridad, la oscilación entre la fascinación y el desencanto por los Estados Unidos como contraposición a los modelos europeos, un quiebre definitivo con "el gigante del norte" ante el avance imperialista estadounidense en el contexto de lucha política por la independencia de Cuba y, finalmente, la constitución de una "modernidad alternativa" encarnada en Nuestra América, donde aparecen los conceptos de "república mestiza" o "democracia americana", bajo los cuales se conjugan elementos tales como "el indio y el vapor, la vincha y la toga, Homero y el legado maya" y, por la cual, en última instancia, el poeta revolucionario da su vida.

Finalmente, en el último ensayo titulado Dilemas de la 'modernidad alternativa', Farías traza conexiones desde todo este cuerpo de ideas de José Martí en torno a una "modernidad alternativa" hacia cuestiones histórico-políticas del pasado más reciente, desde la derrota de los proyectos revolucionarios y las dictaduras cívico-militares-corporativas en los años setenta, hasta el Caracazo en Venezuela, la Guerra del Gas en Bolivia, la crisis argentina del 2001, marcando además una clara diferenciación entre los avances neoliberales sobre el continente y aquellos proyectos políticos que de alguna forma siguen las líneas trazadas por el ideario martiano de Nuestra América, definidos como el "socialismo del siglo XXI".

Dos lúcidos ensayistas evocan en un conjunto de textos amenos y rigurosos el cuerpo de ideas y los puntos más relevantes de las obras de dos escritores clave del siglo XIX. Con una mirada atenta a los detalles y a las conexiones inéditas, con el manejo de una sustancial cantidad de documentación — que rebasa las fronteras de los textos de los dos escritores y se introduce en un mundo de escritos dispersos, de artículos periodísticos, de epistolarios-, Korn y Farías producen estos ensayos donde se ponen en primer plano, se analizan y se problematizan complejas nociones tales como la nación, las fronteras, lo político, la modernidad, la revolución y el estado. El estudio de las ideas y las obras literarias del pasado aparece como modo de reflexionar sobre el presente e interrogar sus certidumbres. Comprender la forma en que se consolidó el Estado nacional argentino a fines del siglo XIX — requiriendo de la matanza y el exterminio de los otros - y los modos en que se produjo el avance (o los desencuentros) de la modernidad en América Latina a expensas de la sangre y el sudor de las mayorías, de los olvidados de la historia-, nos habilita a pensar y reflexionar críticamente sobre nuestra propia actualidad. Como señala Korn en la presentación de sus textos: "Ahora sí, las cartas están echadas". 